\title{
Dictionnaire de Michel de Montaigne, publié sous la direction de PHILIPPE DESAN
}

\section{Sabine Lardon}

\section{(2) OpenEdition}

\section{Journals}

\section{Édition électronique}

URL : http://journals.openedition.org/studifrancesi/33037

DOI : $10.4000 /$ studifrancesi.33037

ISSN : 2427-5856

\section{Éditeur}

Rosenberg \& Sellier

\section{Édition imprimée}

Date de publication : 1 décembre 2005

Pagination : 628

ISSN : 0039-2944

\section{Référence électronique}

Sabine Lardon, «Dictionnaire de Michel de Montaigne, publié sous la direction de PHILIPPE DESAN », Studi Francesi [En ligne], 147 (XLX | III) | 2005, mis en ligne le 01 novembre 2015, consulté le 20 avril 2021 URL : http://journals.openedition.org/studifrancesi/33037 ; DOI : https://doi.org/10.4000/ studifrancesi.33037

Ce document a été généré automatiquement le 20 avril 2021.

\section{(c) (i) (9)}

Studi Francesi è distribuita con Licenza Creative Commons Attribuzione - Non commerciale - Non opere derivate 4.0 Internazionale. 


\title{
Dictionnaire de Michel de Montaigne, publié sous la direction de PHILIPPE DESAN
}

\author{
Sabine Lardon
}

\section{RÉFÉRENCE}

Dictionnaire de Michel de Montaigne, publié sous la direction de PHILIPPE DESAN, Paris, Champion, 2004, pp. 1059.

1 Ce travail monumental a réuni 94 spécialistes de Montaigne, issus de 10 pays différents, qui ont apporté leur collaboration pour un ou plusieurs articles. Dans son introduction, Philippe Desan précise le but de l'ouvrage: «Un Dictionnaire de Montaigne se devait d'intégrer la biographie de l'auteur et de ses proches, de faire le point sur l'histoire éditoriale de l'œuvre, de fournir une image de sa réception mondiale, et enfin de recenser les concepts les plus importants des Essais»(p. 9). A cette fin, le choix, forcément subjectif, des entrées, a conduit à privilégier «la qualité sur la quantité» (ibid.), en évitant de multiplier les entrées de portée trop restreinte. Chaque entrée s'accompagne d'une très utile bibliographie, de renvois à d'autres entrées et, éventuellement, d'un relevé des sources, c'est-à-dire des occurrences dans l'œuvre. Ces entrées balaient des domaines très différents. Les entrées sous formes de nom propre renvoient aux personnages que Montaigne évoque dans son œuvre. Cela va d'Alcibiade (p. 16) à Theodor Zwinger (p. 1048-1049), que Montaigne a rencontré à Bâle et qu'il évoque par le biais d'une périphrase dans son Journal de Voyage. Quant aux entrées sous forme de nom commun, elles permettent d'envisager, entre autres, les principaux aspects de l'écriture de Montaigne (par exemple: Manière-Maniérisme, Citation, Style, Désordre, Essai, Moi, Langue, etc.), l'histoire du texte (Ecriture, Edition de 1580, Edition de 1582, Edition de 1587,... Manuscrits de Montaigne, L'Angelier, Naigeon, etc.), l'auteur et sa famille (Montaigne - 4 entrées - Eyquem de Montaigne - 3 entrées - La Chassaigne, Frères et 
sœurs de Montaigne, Enfance-Enfant(s), etc.), la pensée de Montaigne (Pyrrhon-Pyrrhonisme, Septicisme, Sextus Empiricus, Socrate, Epicure-Epicurisme, Stoïcisme, etc.), ainsi que les grands thèmes de l'œuvre. Ce résumé est loin d'épuiser la richesse d'un ouvrage qui se veut une «somme des études montaignistes» (p. 10) et qui se révèle un outil critique très maniable, utile, voire indispensable, à tous ceux qui lisent Montaigne, l'étudient ou l'enseignent. 